\title{
Microalgae lipids as a feedstock for the production of benzene
}

\author{
Dennis Pingen, (D) Julia Zimmerer, (iD) Nele Klinkenberg and Stefan Mecking (iD * \\ A two-step one-pot synthesis of benzene from the five-fold unsaturated fatty acid eicosapentaenoic acid \\ (EPA), a component of microalgae oils, is presented. By a sequence of olefin metathesis and the catalytic \\ dehydrogenation of the resulting 1,4-cyclohexadiene, two equivalents of benzene are effectively formed \\ per EPA substrate molecule. As the only major by-products, 5-octenoic acid and 5-decenedioic acid are \\ formed. Performing the dehydrogenation step under hydrogen pressure results in the formation of their \\ saturated analogues, sebacic acid and octanoic acid, both desirable products, while the simultaneous \\ dehydrogenation step to benzene is not hampered.
}

\section{Introduction}

Aromatics are essential key compounds of the chemical industry. In particular, benzene is the starting material for the production of numerous agrochemical and pharmaceutical actives, dyes and other chemicals. In view of the finite nature of petrochemical sources and the environmental impact of fossil fuel recovery, schemes that provide access to aromatics from renewable sources are desirable in the long term.

In principle, aromatics occur in large amounts in lignin. However, lignin is a complex mixture containing numerous oxygenated substituted benzene motifs linked to a high molar mass biopolymer. Efforts to produce single clean aromatic compounds by breaking down lignin efficiently have not been successful to date. ${ }^{1,2}$ Thus, lignin is used as a low value fuel for the very largest part. $^{3}$ Possible schemes for the efficient generation of benzene utilizing suitable renewable molecules are lacking.

We now report on the catalytic generation of benzene from eicosapentaenoic acid (EPA). EPA is contained in substantial amounts in various microalgae or can also be produced by yeasts. ${ }^{4-6}$ While the limited achievable cell densities are currently a bottleneck for their production, microalgae offer the benefit of not competing with food production for arable land and fresh water, and they reproduce very rapidly to yield high oil content biomass. ${ }^{7-13}$

Chair of Chemical Materials Science, Universitätsstrasse 10, University of Konstanz, Konstanz, Germany. E-mail: Stefan.Mecking@uni-konstanz.de

\section{Results and discussion}

Towards this aim, we pursued ring closure by olefin metathesis with subsequent dehydrogenation to yield benzene (Scheme 1). For this concept, it is notable that olefin metathesis by ruthenium alkylidenes has been shown to be compatible with fatty acid substrates, plant oils and other renewable feedstocks. ${ }^{14-18}$ Also, the catalytic dehydrogenation of sixmembered cyclic olefins to benzene, driven by the stability of the aromatic systems, is a proven reaction. ${ }^{19,20}$

Olefin metathesis usually converts the substrates into an equilibrium mixture of all possible products accessible by the formal cleavage of the double bonds and recombination of the methylidene fragments. For multiple unsaturated substrates like EPA, a large range of linear and cyclic products are conceivable. Advantageously, 1,4-cyclohexadiene is a thermodynamic sink. ${ }^{21-23}$ This not only favours the formation of this desired product, but ideally also strongly reduces the number of further products formed, namely 5-octeneoic acid, 5-decenedioic acid and 3-hexene which are the result of net EPA chainend homo-metathesis (Scheme 1).

Towards the aim of an efficient self-metathesis reaction of eicosapentaenoic acid, we screened a range of commercial metathesis catalysts (Fig. 1).

The metathesis reactions were run until no change in the composition of the reaction mixture occurred anymore, as observed by GC. These times appeared to vary from 4 hours, which the Grubbs $2^{\text {nd }}$ generation catalyst required (Table 1 , entry 2), to 15 minutes, when Hoveyda-Grubbs 2 achieved its maximum conversion (Table 1, entry 5). In all cases, the productivity was high; the lowest conversion achieved reached $93 \%$ with the Grubbs $1^{\text {st }}$ generation catalyst (Table 1 , entry 1 ). The selectivity towards 1,4-cyclohexadiene was however, not always complete. In most cases this appeared to be around 70 


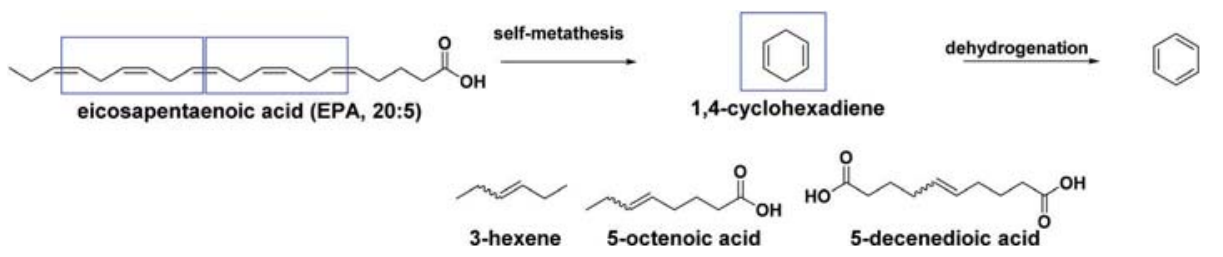

Scheme 1 Self-metathesis of eicosapentaenoic acid, and a possible subsequent homo-metathesis of the produced 5-octenoate to produce 3-hexene and 5-decenedioate, and two equivalents of benzene after dehydrogenation.

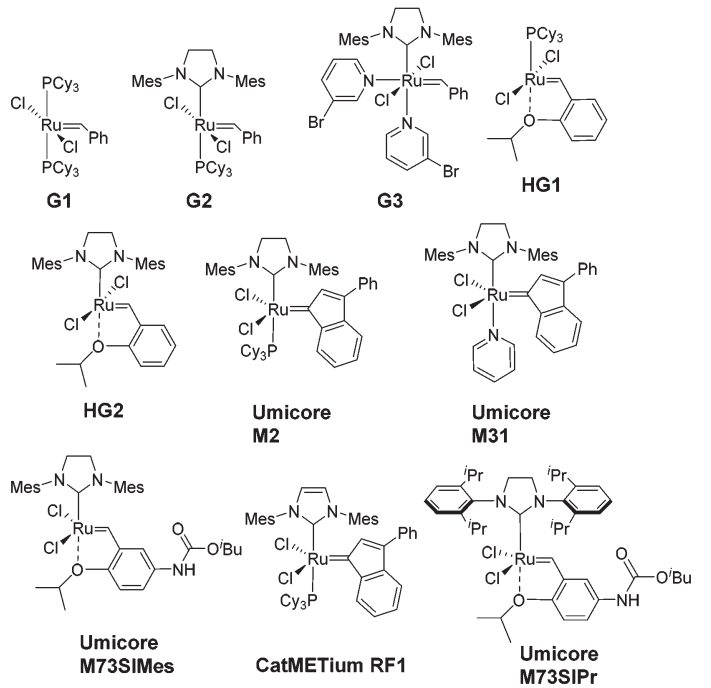

Fig. 1 Metathesis catalysts employed in the screening of eicosapentaenoic acid metathesis.

to $80 \%$, where catMETium was much lower (55\%, Table 1 , entry 6$)$ and Hoveyda-Grubbs $2(100 \%$, Table 1, entry 5) provided the highest selectivity. Overall, 5-octenoate and 5-decenedioic acid were the main remaining additional products. The 5-decenedioic acid results from 5-octenoic self-metathesis or direct EPA chain metathesis. These products are observed as a mixture of both in their thermodynamic equilibrium from the metathesis, about $50 \%$ of 5 -octenoic acid and $25 \%$-decene- dioic acid. The remaining 3-hexene was not observed due to the overlap with the solvent signal (Fig. S2, ESI†). In only a few cases (entries 1, 2 and 4, Table 1) the metathesis was incomplete and multi-unsaturated linear products were observed. All in all, the Hoveyda-Grubbs $2^{\text {nd }}$ generation catalyst appears to be the most suitable catalyst for the self-metathesis of EPA, achieving a maximum conversion and selectivity for 1,4cyclohexadiene.

For the dehydrogenation, different solid-supported Pd catalysts were studied, initially employing neat 1,4-cyclohexadiene as a substrate. This showed the presence of a solvent to be beneficial to perform the dehydrogenation efficiently. A hydrogen acceptor however, was not required although hydrogen is expelled from 1,4-cyclohexadiene to form benzene (ESI, $\dagger$ vide infra). Complete conversion to benzene was observed in these experiments under suitable reaction conditions.

Based on these, in view of a straightforward one-pot procedure, olefin metathesis was carried out in the presence of a solvent, and without any further purification, a solid dehydrogenation catalyst was added and the reaction mixture was heated to optimum dehydrogenation conditions (Table 2). It could be expected that the non-cyclic mono-unsaturated molecules (5-octenoate, or 5-decenedioate) present in the postmetathesis mixture of eicosapentaenoic acid might serve as a hydrogen acceptor. ${ }^{19,20,24,25}$ This was however, not observed to a large extent; only a small portion of octanoate and decanedioic acid was found at most, whereas the major part of the unsaturated linear molecules was unaffected (apart from some double bond isomerization; Fig. S6, ESI $\dagger$ ).

Table 1 Productivity of several metathesis catalysts in the self-metathesis of EPA

\begin{tabular}{|c|c|c|c|c|c|}
\hline Entry & Metathesis cat. (Fig. 1) & Time (min) & Conv. $^{a}(\%)$ & 1,4-CHD select. ${ }^{a}(\%)$ & Main (by) product $^{a}$ \\
\hline 1 & G1 & 60 & 93 & 70 & Undecadienoate $^{b}$ \\
\hline 2 & G2 & 240 & 100 & 93 & Multiple unsat. $^{b}$ \\
\hline 3 & G3 & 15 & 100 & 78 & 5-Octenoate \\
\hline 4 & HG1 & 60 & 100 & 94 & Undecadienoate $^{b}$ \\
\hline 5 & HG2 & 15 & 100 & 100 & 5-Octenoate \\
\hline 6 & CatMETium RF1 & 75 & 99 & 55 & 5-Octenoate \\
\hline 7 & Umicore M2 & 105 & 99 & 78 & 5-Octenoate \\
\hline 8 & Umicore M31 & 75 & 100 & 72 & 5-Octenoate \\
\hline 9 & Umicore M73 SIPr & 75 & 100 & 91 & 5-Octenoate \\
\hline 10 & Umicore M73 SIMes & 105 & 99 & 84 & 5-Octenoate \\
\hline
\end{tabular}

Conditions: Eicosapentaenoic acid ( $5 \mathrm{mmol})$, metathesis catalyst (0.005 mmol, $0.1 \mathrm{~mol} \%)$, neat, $45^{\circ} \mathrm{C} .{ }^{a}$ Determined via $\mathrm{GC}$ analysis. Conversion is determined on the EPA consumption. The selectivity was determined with respect to the maximum theoretical amount (2 equiv. of 1,4 -cyclohexadiene per EPA starting material). ${ }^{b}$ Incomplete self-metathesis product. 
Table 2 Results of one-pot metathesis and the dehydrogenation of eicosapentaenoic acid to benzene

\begin{tabular}{|c|c|c|c|c|}
\hline Entry & $\begin{array}{l}\text { Dehydrogenation catalyst } \\
\text { (loading) }\end{array}$ & $\begin{array}{l}\text { Metathesis conv. and } \\
\text { select. for } 1,4-\mathrm{CHD}^{a}\end{array}$ & Conv. of $1,4-\mathrm{CHD}^{a}(\%)$ & $\begin{array}{l}\text { Overall benzene } \\
\text { select. }^{a, b}(\%)\end{array}$ \\
\hline $1^{b, c}$ & $\mathrm{Pd} / \mathrm{C}(1 \mathrm{~mol} \%)$ & 100 & 100 & 75 \\
\hline $3^{c}$ & $\mathrm{Pd} / \mathrm{C}(1 \mathrm{~mol} \%)$ & 99 & 99 & 87 \\
\hline 4 & $\mathrm{Pd} / \mathrm{C}(1 \mathrm{~mol} \%)$ & 99 & 99 & 76 \\
\hline 5 & $\mathrm{Pd}(\mathrm{OAc})_{2}(1 \mathrm{~mol} \%)$ & 99 & 99 & 67 \\
\hline 6 & $\mathrm{Pd} / \mathrm{Al}_{2} \mathrm{O}_{3}(0.1 \mathrm{~mol} \%)$ & 99 & 99 & 66 \\
\hline
\end{tabular}

Conditions: HG2 (0.005 mmol, $0.1 \mathrm{~mol} \%), 10 \mathrm{~mL}$ toluene solvent, $15 \mathrm{~min}$ at $45{ }^{\circ} \mathrm{C}$, then addition of the supported Pd catalyst and $110{ }^{\circ} \mathrm{C}$ for $20 \mathrm{~h} .{ }^{a}$ Analysed by GC, the conversion of the metathesis was determined with respect to the EPA consumption. The selectivity of 1,4 -cyclohexadiene and benzene was determined with respect to the maximum theoretical amount of 2 equiv. 1,4 -cyclohexadiene from EPA. ${ }^{b} 0.2$ equiv. AMS (anthraquinone-2-sulfonic acid sodium salt) added as a hydrogen acceptor. ${ }^{c}$ Chlorobenzene instead of toluene as a solvent. ${ }^{d}$ Reaction performed in a single step: HG 2 and Pd catalysts were placed in a Schlenk tube under an inert atmosphere, solvent and then EPA were added, and the mixture was heated to $110{ }^{\circ} \mathrm{C}$ and stirred for $20 \mathrm{~h}$.

The metathesis was not adversely influenced by the presence of a solvent; full and selective conversion to 1,4-cyclohexadiene was retained $(\mathrm{ESI}+)$. The presence of a residual ruthenium catalyst is not detrimental to the catalytic dehydrogenation, though the conversion to benzene appeared to be slightly affected in the case of using the post-metathesis reaction mixture. This was also found when employing the other previously tested Pd precursors (Table 2, entries 5 and 6).

As the metathesis is the faster reaction, we investigated whether both reactions could be combined into a single step (Table 2, entry 7), that is combining the substrate, solvent and both catalysts in the initial reaction mixture and gradually heating to the dehydrogenation temperature of $110{ }^{\circ} \mathrm{C}$. Unfortunately, the metathesis step was now hampered and did not reach full conversion (38\%). The subsequent dehydrogenation did proceed relatively well; all in all a total selectivity towards benzene of $28 \%$ based on EPA was achieved.

Although the unsaturated linear $\mathrm{C}_{10}$ diacid and $\mathrm{C}_{8}$ monoacid are useful compounds, their saturated analogues are often preferred. In particular, sebacic acid is in strong demand. As the dehydrogenation catalyst employed can also affect hydrogenation according to the concept of microscopic reversibility, we probed whether this hydrogenation, however could be affected in parallel to the formation of benzene by hydrogenation.

In order to identify suitable reaction conditions, post-metathesis/post-dehydrogenation mixtures were subjected to hydrogenation under $\mathrm{H}_{2}$ pressure (Table 3, entries 1 and 2). Even at only 5 bar hydrogen pressure, the unsaturated 5-octenoic acid and 5-decenedioic acid were fully hydrogenated. With this insight, the metathesis/dehydrogenation reactions were performed according to the aforementioned protocol, but with hydrogen present during the dehydrogenation step (Table 3, entries 3 to 5).

Indeed, benzene formation still occurs at these hydrogen pressures due to the high driving force of aromatization, while at the same time the linear olefinic compounds are hydrogenated effectively (Scheme 2). Note that the composition of the (saturated) acids is shifted in favour of sebacic acid beyond the 2:1 molar ratio expected from a metathesis equilibrium. Possibly, the diacid is hydrogenated more rapidly, and shifts the ongoing metathesis by this removal of the metathesis product. The hydrogen released in the dehydrogenation to benzene is exactly the amount required to hydrogenate the remaining non-cyclic unsaturated molecules; the partial pressure of the hydrogen evolved apparently is not sufficient to actually perform the olefin hydrogenation.

Table 3 Hydrogenation of mixtures containing benzene formed in the 2-step metathesis and dehydrogenation reactions of 1,4-cyclohexadiene formed in the EPA metathesis reactions

\begin{tabular}{|c|c|c|c|c|c|c|c|}
\hline \multirow[b]{2}{*}{ Entry } & \multirow[b]{2}{*}{$\mathrm{H}_{2}$ (bar) } & \multirow{2}{*}{$\begin{array}{l}\text { Conv. of (found) } \\
1,4-\mathrm{CHD}^{a}(\%)\end{array}$} & \multirow[b]{2}{*}{$\mathrm{C}_{6} \mathrm{H}_{6}$ select. $^{a}(\%)$} & \multirow{2}{*}{$\begin{array}{l}\text { Hydrogenation selectivity } \\
\text { of linear olefins (\%) }\end{array}$} & \multicolumn{3}{|c|}{ Composition of saturated linear acid portion (mol\%) } \\
\hline & & & & & $8: 0 \operatorname{Acid}^{a}(\%)$ & 1,10-Diacid ${ }^{a}(\%)$ & Other products $^{b}(\%)$ \\
\hline \multicolumn{8}{|c|}{ Hydrogenation on the post-metathesis, post-dehydrogenation mixture: } \\
\hline 1 & 5 & 100 & 99 & 100 & 56 & 39 & 5 \\
\hline 2 & 10 & 100 & 100 & 100 & 44 & 38 & 18 \\
\hline \multicolumn{8}{|c|}{ Simultaneous post-metathesis dehydrogenation/hydrogenation: } \\
\hline 3 & 5 & 100 & 96 & 100 & 25 & 75 & 0 \\
\hline 5 & 1 & 100 & 98 & 89 & 75 & 25 & 0 \\
\hline
\end{tabular}

Conditions: EPA (5 mmol), HG2 (0.005 mmol, $1 \mathrm{~mol} \%), 45{ }^{\circ} \mathrm{C}, 30 \mathrm{~min}$, then toluene $(10 \mathrm{~mL}), \mathrm{Pd} / \mathrm{C}(10 \% \mathrm{w} / \mathrm{w}, 1 \mathrm{~mol} \%), 110{ }^{\circ} \mathrm{C}, 20 \mathrm{~h}$. ${ }^{a}$ Determined via GC analysis. Selectivity was determined with respect to the maximum theoretical amount based on EPA. ${ }^{b}$ Other products are the result of incomplete metathesis. These consist mainly of undecadienoates. 


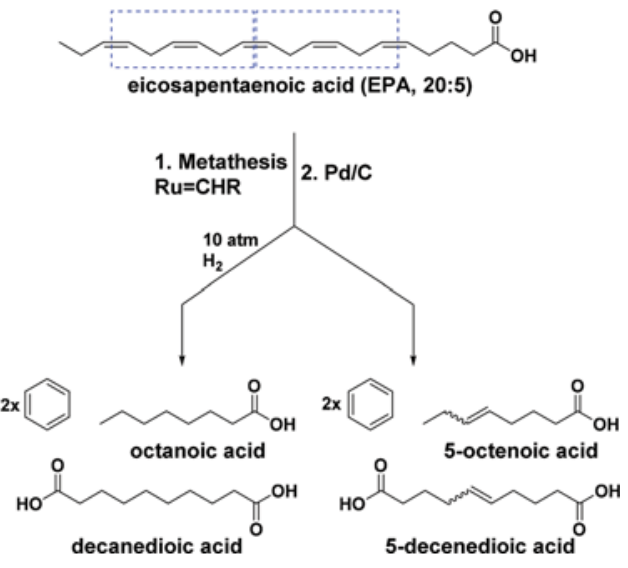

Scheme 2 Self-metathesis and the subsequent dehydrogenation of EPA resulting in benzene, 5-decenedioic acid and 5-octenoic acid in the absence of hydrogen. In the presence of even 1 atmosphere hydrogen, benzene and the saturated compound are formed.

\section{Conclusions}

The one-pot procedure of catalytic metathesis and dehydrogenation enables an efficient production of benzene from eicosapentaenoic acid. The latter is a component of microalgae oil feedstocks, amongst others. This avenue overcomes the current lack of routes to desirable individual aromatic compounds from renewable sources, rather than complex mixtures of oxygenated aromatics which are also not separable. Benzene is essential for the production of many actives, dyes and other chemicals. As the only major by-products, decenedioic acid and octenoic acid are formed. Remarkably, these can be hydrogenated simultaneously to the dehydrogenation step to form their saturated analogues. In particular, sebacic acid is in strong demand for high-performance polyamides, corrosion protection and other applications.

While the production of benzene from fatty acids is certainly not economically viable today, this scheme does provide a perspective to access this important building block from non-fossil sources efficiently.

\section{Experimental}

\section{General considerations}

All reactions were performed under an inert gas atmosphere and mixed using a magnetic stirring bar, unless stated otherwise. Chlorobenzene was degassed and stored over molecular sieves under an inert atmosphere, toluene was distilled over $\mathrm{Na}$ and stored under an inert atmosphere, and methanol was distilled over $\mathrm{Mg}$ and stored over molecular sieves under an inert atmosphere. Ethyl vinyl ether (EVE), 1,4-cyclohexadiene and anthraquinone-2-sulfonic acid sodium salt (AMS) were obtained from Sigma-Aldrich and used as received. Eicosapentaenoic acid (EPA) and the Hoveyda-Grubbs $2^{\text {nd }}$ generation catalyst were purchased from Carbosynth and used as received. EPA was distilled before use. $\mathrm{Pd} / \mathrm{C}(10 \%), \mathrm{Pd} / \mathrm{Al}_{2} \mathrm{O}_{3}$ $(5 \%)$ and $\mathrm{Pd}(\mathrm{OAc})_{2}$ were obtained from ABCR. The metathesis catalyst precursors, Grubbs $1^{\text {st }}$ generation, Grubbs $2^{\text {nd }}$ generation, Grubbs $3^{\text {rd }}$ generation and Hoveyda-Grubbs $1^{\text {st }}$ generation, were purchased from Sigma-Aldrich and used as received. CatMETetium was purchased from ABCR. Umicore metathesis catalyst precursors were kindly donated by Umicore. Hydrogen (N5.0, 99.999\%) was obtained from Air Liquide. Gas chromatography was performed on a PerkinElmer GC Clarus 500 system equipped with an elite-5 column (length $=30 \mathrm{~m}$, inner diameter $=0.25 \mathrm{~mm}$, thickness $=25 \mu \mathrm{m}$ ) and a FID detector via the following programs: $1 \mathrm{~min}$ at $90^{\circ} \mathrm{C}$, $30{ }^{\circ} \mathrm{C} \min ^{-1}$ to $280{ }^{\circ} \mathrm{C}, 280{ }^{\circ} \mathrm{C}$ for 8 minutes (method 1), or $3 \mathrm{~min}$ at $50{ }^{\circ} \mathrm{C}, 20^{\circ} \mathrm{C} \mathrm{min}^{-1}$ to $280{ }^{\circ} \mathrm{C}, 280{ }^{\circ} \mathrm{C}$ for 5 minutes (method 2), both with an injector temperature of $300{ }^{\circ} \mathrm{C}$ and a detector temperature of $280{ }^{\circ} \mathrm{C}$. GC-MS measurements were conducted on an Agilent GC7890A system equipped with an inert MSD 5975C triple-axis detector. The column in the GC-MS was an HP-5 ms. NMR spectra were recorded on a Bruker Avance III $400 \mathrm{MHz}$ spectrometer. ${ }^{1} \mathrm{H}$ NMR spectra were referenced to the residual protiated solvent $\left(\mathrm{CDCl}_{3}\right)$.

\section{Catalysis}

Procedure for the metathesis of eicosapentaenoic acid. In the glovebox, the appropriate metathesis catalyst precursor (0.005 mmol, $0.1 \mathrm{~mol} \%$ ) was weighed into a Schlenk tube. The Schlenk tube was closed with a septum and transferred out of the glovebox. Under an inert atmosphere, eicosapentaenoic acid ( $5 \mathrm{mmol}$ ) was added via a syringe. At time intervals of $0,15,30,45,75,105,180$ and 240 minutes, samples were taken via a syringe from the reaction mixture. The sample was quenched with EVE and filtered over silica to remove all metal residues. The sample was subsequently analysed by GC.

Procedure for the dehydrogenation of 1,4-cyclohexadiene. The appropriate $\mathrm{Pd}$ source $(\mathrm{Pd} / \mathrm{C}(10 \% \mathrm{w} / \mathrm{w})$ 5-0.1 mol\%, $\left.\mathrm{Pd}(\mathrm{OAc})_{2} 1 \mathrm{~mol} \%, \mathrm{Pd} / \mathrm{Al}_{2} \mathrm{O}_{3}(5 \% \mathrm{w} / \mathrm{w}) 1-0.1 \mathrm{~mol} \%\right)$ was loaded into a Schlenk tube. In case AMS or dimethylfumarate was applied, these were added $(0.2 \mathrm{mmol}, 62.1 \mathrm{mg}$ or 1 equiv., $1.44 \mathrm{~g}, 0.25$ equiv., $360 \mathrm{mg}$, respectively). The Schlenk tube was closed with a septum and evacuated and purged with $\mathrm{N}_{2}$ 3 times. Using a syringe, the solvent (chlorobenzene or toluene) was added, followed by the addition of 1,4-cyclohexadiene (10 mmol), also via a syringe. The reaction mixture was then heated to the stated temperature and stirred for the appropriate time. After this time, the reaction mixture was cooled to room temperature and a sample was taken from the mixture and filtered over silica to remove any catalyst. The sample was analysed by GC.

Procedure for the single-step one-pot metathesis and dehydrogenation

One-step procedure. In a Schlenk tube, Pd/C 10\% w/w ( $0.1 \mathrm{mmol}, 1 \mathrm{~mol} \%$ ) was weighed, and the tube was evacuated and purged with an inert gas. To this, Hoveyda-Grubbs $2^{\text {nd }}$ generation catalyst $(0.005 \mathrm{mmol}, 0.1 \mathrm{~mol} \%)$ was added in the glovebox. The Schlenk tube was closed with a septum and transferred out of the glovebox. Using a syringe, chlorobenzene 
or toluene $(10 \mathrm{~mL})$ was added, followed by the addition of eicosapentaenoic acid $(5 \mathrm{mmol})$. The mixture was heated to $110{ }^{\circ} \mathrm{C}$ over the course of 25 minutes and then stirred at this temperature for $20 \mathrm{~h}$. After the reaction mixture was cooled to room temperature, a sample was filtered over silica and analysed by GC.

Procedure for the two-step one-pot metathesis and dehydrogenation. In a Schlenk tube, the Hoveyda-Grubbs $2^{\text {nd }}$ generation catalyst $(0.005 \mathrm{mmol}, 0.1 \mathrm{~mol} \%$ ) was weighed in the glovebox. The Schlenk tube was closed with a septum and transferred out of the glovebox. Using a syringe, chlorobenzene or toluene $(10 \mathrm{~mL})$ was added. The mixture was heated to $45^{\circ} \mathrm{C}$ and eicosapentaenoic acid (5 mmol) was added. The mixture was stirred for $15 \mathrm{~min}$. After this, Pd/C $10 \% \mathrm{w} / \mathrm{w}(0.1 \mathrm{mmol}$, $1 \mathrm{~mol} \%$ ) was added and the entire mixture was further heated to $110{ }^{\circ} \mathrm{C}$ and stirred at this temperature for $20 \mathrm{~h}$. After the reaction mixture was cooled to room temperature, a sample was filtered over silica and analysed by GC.

Procedure for the two-step one-pot metathesis and dehydrogenation in the presence of $\mathbf{H}_{2}$. In a Schlenk tube, the Hoveyda-Grubbs $2^{\text {nd }}$ generation catalyst $(0.005 \mathrm{mmol}$, $0.1 \mathrm{~mol} \%$ ) was weighed in the glovebox. The Schlenk tube was closed with a septum and transferred out of the glovebox. Using a syringe, preheated eicosapentaenoic acid (5 mmol) was added. The mixture was stirred for $15 \mathrm{~min}$. A balloon filled with $\mathrm{H}_{2}$ was connected to the Schlenk tube via a needle. A suspension of $\mathrm{Pd} / \mathrm{C} 10 \% \mathrm{w} / \mathrm{w}(0.1 \mathrm{mmol}, 1 \mathrm{~mol} \%)$ in toluene $(10 \mathrm{~mL})$ was added and the entire mixture was further heated to $110{ }^{\circ} \mathrm{C}$ and stirred at this temperature for $20 \mathrm{~h}$. After the reaction mixture was cooled to room temperature, a sample was filtered over silica and analysed by GC.

In the case of the experiments with 5 and 10 bar $\mathrm{H}_{2}$, the metathesis mixture was transferred to a stainless steel autoclave and a suspension of $\mathrm{Pd} / \mathrm{C} 10 \% \mathrm{w} / \mathrm{w}$ (0.1 mmol, $1 \mathrm{~mol} \%)$ in toluene $(10 \mathrm{~mL})$ was added. The autoclave was pressurized with the appropriate $\mathrm{H}_{2}$ pressure and heated to $110{ }^{\circ} \mathrm{C}$ for $20 \mathrm{~h}$. After the reaction mixture was cooled to room temperature, a sample was filtered over silica and analysed by GC.

\section{Conflicts of interest}

The authors declare no conflict of interests.

\section{Acknowledgements}

D. P. gratefully acknowledges a Marie Curie Zukunftskolleg Incoming Fellowship.

\section{Notes and references}

1 A. Kaiho, M. Kogo, R. Sakai, K. Saito and T. Watanabe, Green Chem., 2015, 17, 2780.
2 C. A. Gasser, M. Čvančarová, E. M. Ammann, A. Schäffer, P. Shahgaldian and P. F.-X. Corvini, Appl. Microbiol. Biotechnol., 2017, 101, 2575.

3 J. Zakzeski, P. C. A. Bruijnincx, A. L. Jongerius and B. M. Weckhuysen, Chem. Rev., 2010, 110, 3552.

4 R. J. Winwood, OCL, 2013, 20, D604.

5 M. L. Hamilton, R. P. Haslam, J. A. Napier and O. Sayanova, Metab. Eng., 2014, 22, 3.

6 Z. Xue, P. L. Sharpe, S.-P. Hong, N. S. Yadav, D. Xie, D. R. Short, H. G. Damude, R. A. Rupert, J. E. Seip, J. Wang, D. W. Pollak, M. W. Bostick, M. D. Bosak, D. J. Macool, D. H. Hollerbach, H. Zhang, D. M. Arcilla, S. A. Bledsoe, K. Croker, E. F. McCord, B. D. Tyreus, E. N. Jackson and Q. Zhu, Nat. Biotechnol., 2013, 31, 734.

7 P. Mäki-Arvela, I. Kubickova, M. Snåre, K. Eränen and D. Y. Murzin, Energy Fuels, 2007, 21, 30.

8 C. Huang, X.-F. Chen, L. Xiong, X.-D. Chen, L.-L. Ma and Y. Chen, Biotechnol. Adv., 2013, 31, 129.

9 P. Roesle, F. Stempfle, S. K. Hess, J. Zimmerer, C. Río Bártulos, B. Lepetit, A. Eckert, P. G. Kroth and S. Mecking, Angew. Chem., Int. Ed., 2014, 53, 6800.

10 Y. Chen, N. Zhao, Y. Wu, K. Wu, X. Wu, J. Liu and M. Yang, Environ. Prog. Sustainable Energy, 2017, 36, 259.

11 T. M. Mata, A. A. Martins and N. S. Caetano, Renewable Sustainable Energy Rev., 2010, 14, 217.

12 C. Ratledge, $O C L, 2013,20$, D602.

13 S. K. Hess, B. Lepetit, P. G. Kroth and S. Mecking, Eur. J. Lipid Sci. Technol., 2018, 120, 1700152.

14 R. T. Mathers, Plant based monomers and polymers, US20130324688A1, 2013.

15 P. J. Deuss, K. Barta and J. G. de Vries, Catal. Sci. Technol., 2014, 4, 1174.

16 S. Chikkali and S. Mecking, Angew. Chem., Int. Ed., 2012, 51, 5802.

17 J. A. M. Lummiss, K. C. Oliveira, A. M. T. Pranckevicius, A. G. Santos, E. N. dos Santos and D. E. Fogg, J. Am. Chem. Soc., 2012, 134, 18889.

18 C. S. Higman, M. P. de Araujo and D. E. Fogg, Catal. Sci. Technol., 2016, 6, 2077.

19 R. J. Rico, M. Page and C. Doubleday, J. Am. Chem. Soc., 1992, 114, 1131.

20 G. Fochi, Organometallics, 1988, 7, 2255.

21 R. T. Mathers, M. J. Shreve, E. Meyler, K. Damodaran, D. F. Iwig and D. J. Kelley, Macromol. Rapid Commun., 2011, 32, 1338.

22 E. Verkuijlen and C. Boelhouwer, J. Chem. Soc., Chem. Commun., 1974, 793.

23 J. Lever, K. Wagner and J. Sworen, Simplified methods of making 1,3-cyclohexadiene, US20030176749A1, 2003.

24 D. Q. Hu, C. D. MacPherson and K. T. Leung, Surf. Sci., 1992, 273, 21.

25 A. V. Iosub and S. S. Stahl, ACS Catal., 2016, 8201. 